\title{
Two-stage nerve graft using a silicone tube
}

\author{
Shayan Abdollah Zadegan ${ }^{1,2}$, Masoumeh Firouzi ${ }^{1,2}$, Mohammad Hossein Nabian ${ }^{2,3}$, \\ Leila Oryadi Zanjani ${ }^{2,3}$ and Reza Shahryar Kamrani ${ }^{3,4 *}$ \\ ${ }^{1}$ Tissue Repair Laboratory, Institute of Biochemistry and Biophysics (IBB), University of Tehran, Tehran, Iran, ${ }^{2}$ Research \\ Center for Neural Repair (RCNR), University of Tehran, Tehran, Iran, ${ }^{3}$ Department of Orthopedic and Trauma Surgery, Shariati \\ Hospital, Tehran University of Medical Sciences, Tehran, Iran, ${ }^{4}$ Joint Reconstruction Research Center, Tehran University of \\ Medical Sciences, Tehran, Iran
}

Keywords: peripheral nerve injuries, tendon injuries, autografts, fibrosis, nerve regeneration

\section{Background and Significance of the Problem}

Peripheral nerve injury (PNI) is a life altering situation with significant morbidity (1). Majority of PNI cases occur in the upper limb $(2,3)$, where the sensory/motor dysfunction and pain, leads to psychological distress and substantial disability in daily socio-economic activities $(1,4-6)$.

In patients with severe concomitant soft tissue injuries, the primary repair of the nerve gap with a graft is usually impossible or unsuccessful $(7,8)$, mainly due to extent of the injury, distortion of the normal topography, excessive scarring, and subsequent adhesion and tethering (7).

A similar situation is also present in reconstruction of scarred flexor tendon system of the hand. Adhesion of the injured tendon to the surrounding soft tissues is a challenge for the hand surgeons. A widely accepted treatment for this condition is two-stage tendon graft (9). This technique was introduced previously to improve the outcome of the tendon reconstruction in unfavorable conditions (10). In 1965, Paneva-Holevich reported a "two-stage tenoplasty," which was modified by Hunter and Salisbury in $1971(11,12)$. The modified technique involved the use of a silicone rod implant in the first stage and grafting through the pseudosheath formed around the silicone in the second stage with a 3-6 month interval (9). This technique of flexor tendon repair was used in different clinical conditions in which the primary repair was not possible or failed. The results were satisfactory and the approach was proved to be reliable for restoring flexor tendon function (9). With the silicone tube implantation in the first stage, a sheath would form around the silicone due to its non-absorbable nature (13). After removing the silicone tube in the second stage, the severely scarred tendon bed would transform into a "smooth well-organized pseudosheath through which a tendon can glide" (14). In this article, we would like to highlight the potential benefits of using a similar two-stage technique in nerve grafts of severely traumatized limbs. This article was submitted to Reconstructive and Plastic Surgery, a section of the journal Frontiers in

Surgery

Received: 17 February 2015

Accepted: 31 March 2015

Published: 23 April 2015

Citation:

Zadegan SA, Firouzi M, Nabian MH,

Zanjani LO and Kamrani RS (2015)

Two-stage nerve graft using a silicone tube.

Front. Surg. 2:12.

doi: 10.3389/fsurg.2015.00012

\section{Current State of the Art and its Limitations}

Although nerve repair strategies have been developed in the last decades, the outcome is still suboptimal and unpredictable, especially in unfavorable conditions $(15,16)$. In the neurotmesis, primary end-to-end repair is the most commonly used technique and the gold standard surgical treatment (17). In presence of a large defect, two nerve ends cannot be approximated without tension. Consequently using a graft or conduit as a bridge will be essential under such circumstances (7). Despite the disadvantages of autograft, such as donor site morbidity and limited length of available graft material, this approach is still the gold standard for nerve bridging; especially for long gaps $(>3 \mathrm{~cm})(7,8,17-$ 19). Shorter gaps can be repaired with different types of conduits. This eliminates the disadvantage of donor site morbidity (7). Various biologic materials such as bone, artery, vein, and skeletal muscle are 
used for conduits as well as synthetic materials $(7,18)$. Synthetic materials with absorbable nature (e.g., polyglycolic acid polymer) are preferred over non-degradable ones (e.g., silicone); because in long term, chronic foreign body reaction produces excessive scar which can interfere with the nerve function and cause the need for the secondary surgical intervention $(13,20)$.

In severe injuries or infected wounds, nerve defect repair is more challenging $(7,8)$. In such cases, after the primary marking of the proximal and distal ends of the nerve, a delayed nerve grafting (approximately 3 weeks to 3 months post-injury) is performed in a secondary procedure (8).

\section{Proposed Strategy and Advantages Over the Current Nerve Repair Approaches}

We propose a two-stage graft approach in repair of the peripheral nerve gaps in severely traumatized limb:

- In the first stage (the primary phase of injury/initial exploration), proximal and distal ends of the transected nerve are determined and the nerve gap is temporarily reconstructed with interposition of a silicone tube.

- In the second stage (after 1-3 months), the silicone tube undergoes encapsulation with the pseudosheath. In this stage, the silicone tube is detached from the surrounding membrane and pulled out without causing any damage to the membrane. The nerve graft segment is interposed through the pseudosheath and the nerve ends are sutured to the ultimate nerve graft.

It is evident from previous studies that the pseudosheath formed around the silicone is not simply a scar layer. Hunter and colleagues showed in an experimental study in a primate model that after 8 weeks, the pseudosheath consists of three layers: (1) the intima that was formed with secretory cells containing vacuoles of glycosaminoglycan that provided a soft and sliding surface, (2) the media that was rich in collagen and provided vascular support, and (3) the adventitia that was highly vascular with loose fibrous tissue (21). The authors described the pseudosheath as a "morphologically stable structure that showed no propensity for longitudinal contracture" (21). The evidence supports the idea that this vascular sheath could provide a suitable bed for the interposed nerve segment (22), as it did for the tendon graft.

In 1979, Lundborg and colleagues evaluated nerve regeneration through a pseudosheath conduit (23). A silastic rod wrapped with a stainless steel spiral was implanted subcutaneously in the back of the rats. After 3 weeks, the produced pseudosheath was transferred and used as a conduit to bridge a 10-12 $\mathrm{mm}$ length gap in the sciatic nerve. Assessment of regeneration after 3 months showed a nerve trunk with small fascicles, surrounded by an epineurium, without any wild uncontrolled growth of axons. In 1980 and 1981, they evaluated the same procedure with electromyography and reported a good functional regeneration of motor fibers $(24,25)$. In 1985, Mackinnon and colleagues used the staged procedure described by Lundborg for ulnar nerve regeneration in a primate model (26). After 6 weeks interval, a coiled wire ensheathed by pseudosheath was produced. A $3-\mathrm{cm}$ segment of the ulnar nerve was excised and the distal and proximal end of the nerve were inserted into the sheath and sutured. After over 9 months of observation, they found regeneration of the primate nerve across a $3-\mathrm{cm}$ gap through the pseudosheath. However, no functional assessment was done and the regeneration across the gap after 9 months was of poorer histologic quality compared with the grafting techniques of that time (26). In 1988, in a more comprehensive study, they found that the quality of regeneration between Sural nerve graft and the pseudosheath was similar (27). Although the basic idea of using pseudosheath as a conduit was brilliant, it lost its importance after new conduits were introduced.

\section{Objective Summary of the Promise and Pitfalls of the Two-Stage Technique}

In two-stage nerve graft, the pseudosheath formed around the silicone tube during the first stage is used as a tunnel to envelope the nerve graft segment in the second stage. This pseudosheath is a suitable bed for the interposed nerve graft because of: (1) the soft and sliding lumen that prevents adhesion and tethering of the interposed nerve graft, (2) good vascularization that provides oxygen and nourishment for the graft, (3) the stable structure that protects the interposed nerve graft from compression.

The most important parameter in this technique is the time between the two stages. This factor plays an influential role in both the nerve regeneration and the pseudosheath maturation. Previous studies showed that axonal regeneration decreases with increasing time after the nerve trauma; mainly due to the decreasing capacity of proximal axons to extend as well as lower proliferation rate and neurotrophic factor production of distal Schwann cells (28). The optimal timing for regeneration is different between animal and human studies. In animal models, axonal regeneration begins to reduce between 1 and 2 months post-injury (29-32) while in clinical studies this time range is $3-5$ months $(7,33,34)$. This optimal timing of nerve regeneration is synchronous with the proper time needed for maturation of the pseudosheath. In clinical practice, the minimum time interval between two stages of tendon graft is $2-3$ months to permit structural maturation of the pseudosheath $(35,36)$. However, electron microscopy in an experimental study on hen shows that after 4 weeks, a pseudosheath comparable to normal parietal sheath is formed around the silicone tube (37)

Clearly, there are two major drawbacks to this technique. The first drawback is the delay of one to three months for grafting the nerve, due to the need for a two-stage operation. The other drawback to this technique is the possible damage to the formed pseudosheath in the second stage. Normally, this technique is not an alternative to nerve grafting when it is possible but it is a solution when the primary nerve grafting is not possible or is disappointing, because of the surrounding scar tissue, which makes it illogical to do primary nerve graft. We believe that the pseudosheath can be beneficial when the nerve defect is large and the outcome of traditional nerve graft or conduits is expected to be disappointing.

In conclusion, this technique combines the advantages of the old technique of the nerve graft and the new technique of the nerve conduit without losing the potential advantages of neither of them. 
It is expected that two-stage nerve graft technique will reduce the adverse effects of the scar in acute phase and improve the outcome of grafting in unfavorable conditions. Future experimental and clinical studies are needed to validate and expand this proposed technique.

\section{References}

1. Novak CB, Anastakis DJ, Beaton DE, Mackinnon SE, Katz J. Biomedical and psychosocial factors associated with disability after peripheral nerve injury. $J$ Bone Joint Surg Am (2011) 93(10):929-36. doi:10.2106/JBJS.J.00110

2. Kouyoumdjian JA. Peripheral nerve injuries: a retrospective survey of 456 cases. Muscle Nerve (2006) 34(6):785-8. doi:10.1002/mus.20624

3. Taylor CA, Braza D, Rice JB, Dillingham T. The incidence of peripheral nerve injury in extremity trauma. Am J Phys Med Rehabil (2008) 87(5):381-5. doi:10. 1097/PHM.0b013e31815e6370

4. Lad SP, Nathan JK, Schubert RD, Boakye M. Trends in median, ulnar, radial, and brachioplexus nerve injuries in the United States. Neurosurgery (2010) 66(5):953-60. doi:10.1227/01.NEU.0000368545.83463.91

5. Ring D. Symptoms and disability after major peripheral nerve injury. Hand Clin (2013) 29(3):421-5. doi:10.1016/j.hcl.2013.04.008

6. Ciaramitaro P, Mondelli M, Logullo F, Grimaldi S, Battiston B, Sard A, et al. Traumatic peripheral nerve injuries: epidemiological findings, neuropathic pain and quality of life in 158 patients. J Peripher Nerv Syst (2010) 15(2):120-7. doi:10.1111/j.1529-8027.2010.00260.x

7. Siemionow M, Brzezicki G. Chapter 8: current techniques and concepts in peripheral nerve repair. Int Rev Neurobiol (2009) 87:141-72. doi:10.1016/ S0074-7742(09)87008-6

8. Ray WZ, Mackinnon SE. Management of nerve gaps: autografts, allografts, nerve transfers, and end-to-side neurorrhaphy. Exp Neurol (2010) 223(1):77-85. doi:10.1016/j.expneurol.2009.03.031

9. Battiston B, Triolo PF, Bernardi A, Artiaco S, Tos P. Secondary repair of flexor tendon injuries. Injury (2013) 44(3):340-5. doi:10.1016/j.injury.2013.01.023

10. O'Shea K, Wolfe SW. Two-stage reconstruction with the modified Paneva-Holevich technique. Hand Clin (2013) 29(2):223-33. doi:10.1016/ j.hcl.2013.02.011

11. Paneva-Holevich E. Two-stage plasty in flexor tendon injuries of fingers within the digital synovial sheath. Acta Chir Plast (1965) 7:112-24.

12. Hunter JM, Salisbury RE. Flexor-tendon reconstruction in severely damaged hands. A two-stage procedure using a silicone-dacron reinforced gliding prosthesis prior to tendon grafting. J Bone Joint Surg Am (1971) 53(5): 829-58.

13. Gu X, Ding F, Yang Y, Liu J. Construction of tissue engineered nerve grafts and their application in peripheral nerve regeneration. Prog Neurobiol (2011) 93(2):204-30. doi:10.1016/j.pneurobio.2010.11.002

14. Culp RW. Reconstruction of flexor tendon with hunter tendon implant. Operat Tech Orthop (1993) 3(4):298-302. doi:10.1016/S1048-6666(06)80019-4

15. Griffin MF, Malahias M, Hindocha S, Khan WS. Peripheral nerve injury: principles for repair and regeneration. Open Orthop J (2014) 8:199-203. doi:10. 2174/1874325001408010199

16. Wood MD, Kemp SWP, Weber C, Borschel GH, Gordon T. Outcome measures of peripheral nerve regeneration. Ann Anat (2011) 193(4):321-33. doi:10.1016/ j.aanat.2011.04.008

17. Grinsell D, Keating CP. Peripheral nerve reconstruction after injury: a review of clinical and experimental therapies. Biomed Res Int (2014) 2014:698256. doi:10.1155/2014/698256

18. Weber RV, Mackinnon SE. Bridging the neural gap. Clin Plast Surg (2005) 32(4):605-16. doi:10.1016/j.cps.2005.05.003

19. Isaacs J, Browne T. Overcoming short gaps in peripheral nerve repair: conduits and human acellular nerve allograft. Hand (N Y) (2014) 9(2):131-7. doi:10. 1007/s11552-014-9601-6

20. Lin MY, Manzano G, Gupta R. Nerve allografts and conduits in peripheral nerve repair. Hand Clin (2013) 29(3):331-48. doi:10.1016/j.hcl.2013.04.003

21. Hunter JM, Jaeger SH, Matsui T, Miyaji N. The pseudosynovial sheath - its characteristics in a primate model. J Hand Surg Am (1983) 8(4):461-70. doi:10. 1016/S0363-5023(83)80209-3

\section{Acknowledgments}

The authors would like to thank Dr. Nashid Nabian and Dr. Kaveh Boveiri for their careful language editing. Funding: There were no special grants for this study.

22. Wolford LM, Stevao ELL. Considerations in nerve repair. Proc (Bayl Univ Med Cent) (2003) 16(2):152-6.

23. Lundborg G, Hansson HA. Regeneration of peripheral nerve through a preformed tissue space. Preliminary observations on the reorganization of regenerating nerve fibres and perineurium. Brain Res (1979) 178(2-3):573-6. doi:10. 1016/0006-8993(79)90716-9

24. Lundborg G, Hansson HA. Nerve regeneration through preformed pseudosynovial tubes. A preliminary report of a new experimental model for studying the regeneration and reorganization capacity of peripheral nerve tissue. J Hand Surg Am (1980) 5(1):35-8. doi:10.1016/S0363-5023(80)80041-4

25. Lundborg G, Dahlin LB, Danielsen NP, Hansson HA, Larsson K. Reorganization and orientation of regenerating nerve fibres, perineurium, and epineurium in preformed mesothelial tubes - an experimental study on the sciatic nerve of rats. J Neurosci Res (1981) 6(3):265-81. doi:10.1002/jnr.490060302

26. Mackinnon SE, Dellon AL, Hudson AR, Hunter DA. Nerve regeneration through a pseudosynovial sheath in a primate model. Plast Reconstr Surg (1985) 75(6):833-41. doi:10.1097/00006534-198506000-00014

27. Mackinnon SE, Dellon AL. A comparison of nerve regeneration across a sural nerve graft and a vascularized pseudosheath. J Hand Surg Am (1988) 13(6):935-42. doi:10.1016/0363-5023(88)90275-4

28. Kuffler DP. An assessment of current techniques for inducing axon regeneration and neurological recovery following peripheral nerve trauma. Prog Neurobiol (2014) 116:1-12. doi:10.1016/j.pneurobio.2013.12.004

29. Gordon T, Sulaiman O, Boyd JG. Experimental strategies to promote functional recovery after peripheral nerve injuries. J Peripher Nerv Syst (2003) 8(4):236-50. doi:10.1111/j.1085-9489.2003.03029.x

30. Belkas JS, Munro CA, Shoichet MS, Midha R. Peripheral nerve regeneration through a synthetic hydrogel nerve tube. Restor Neurol Neurosci (2005) 23(1):19-29.

31. Sulaiman OA, Gordon T. Effects of short- and long-term Schwann cell denervation on peripheral nerve regeneration, myelination, and size. Glia (2000) 32(3):234-46. doi:10.1002/1098-1136(200012)32:3<234:: AID-GLIA40>3.0.CO;2-3

32. Hall SM. The biology of chronically denervated Schwann cells. Ann N Y Acad Sci (1999) 14(883):215-33. doi:10.1111/j.1749-6632.1999.tb08584.x

33. Jones RHB. Repair of the trigeminal nerve: a review. Aust Dent J (2010) 55(2):112-9. doi:10.1111/j.1834-7819.2010.01216.x

34. Terzis JK, Kokkalis ZT. Outcomes of secondary reconstruction of ulnar nerve lesions: our experience. Plast Reconstr Surg (2008) 122(4):1100-10. doi:10.1097/ PRS.0b013e3181858f67

35. Kontogeorgakos V, Koutalos A, Hantes M, Manoudis G, Badras L, Malizos K. Traumatic tibialis anterior tendon rupture: treatment with a two-stage silicone tube and an interposition hamstring tendons graft protocol. Knee Surg Sports Traumatol Arthrosc (2013) 23(3):875-8. doi:10.1007/s00167-013-2544-6

36. Eskeland G, Eskeland T, Hovig T, Teigland J. The ultrastructure of normal digital flexor tendon sheath and of the tissue formed around silicone and polyethylene implants in man. J Bone Joint Surg Br (1977) 59(2):206-12.

37. Takasugi H, Inoue H, Akahori O. Scanning electron microscopy of repaired tendon and pseudosheath. Hand (1976) 8(3):228-34. doi:10.1016/0072-968X(76) 90006- 1

Conflict of Interest Statement: The authors declare that the research was conducted in the absence of any commercial or financial relationships that could be construed as a potential conflict of interest.

Copyright (C) 2015 Zadegan, Firouzi, Nabian, Zanjani and Kamrani. This is an openaccess article distributed under the terms of the Creative Commons Attribution License (CC BY). The use, distribution or reproduction in other forums is permitted, provided the original author(s) or licensor are credited and that the original publication in this journal is cited, in accordance with accepted academic practice. No use, distribution or reproduction is permitted which does not comply with these terms. 